belong to the Royal College of General Practitioners and yet are making strong endeavours to update themselves, often against heavy odds, into the era of 1981, getting themselves either into or close to computerisation, resuscitation, self-audit, etc. I would only like to suggest to those who think that the college should remain a closed shop that this is probably not in the long term in its own best interest, and that some form of associate membership, as has been mentioned on the basis of inspection of how practices are organised and work, may be a viable way of having additional valuable membership.

Perhaps it would not be inappropriate to point out that all doctors have in the past put themselves through a somewhat extensive examination system, and for various reasons may not wish to be forever taking yet more examinations. We all know from experience that examinations are of very limited value: they show only that a person has a potential but do not prove that the potential will, in fact, be used. May I suggest that the readers and the college meditate on some of these points?

Highcliffe, Dorset BH23 5ET

\section{S HarCourt-Webster}

\section{Doctors' pay}

SIR,-Many doctors, though dismayed that the Government should have betrayed the principle of determining doctors' pay, will nevertheless have sympathy with the need to relate public expenditure to what the country can afford.

The public sector has become a great burden on the exchequer, mainly because it has become relatively too large and has been plagued by overmanning, restrictive practices, inefficiency, and high administrative costs. None of these criticisms can be levelled at NHS doctors, who have provided, to use the classification of Which? magazine, if not "best buy" certainly "good value for money" under difficult circumstances since 1948

Unless the Government can offer a "carrot" to public sector workers by assuring them of a return to direct comparability with private industry once they have put their respective houses in order, there can be no hope of a rational and acceptable pay policy which is fair to all. For a start, the Government could make an example of doctors by promising them a fully up-to-date Review Body award in 1982.

CHRISTOPHER MAYCOCK

Crediton, Devon

SIR,-I have read today in Doctor that the Review Body, whose annual report has just been made public, has decided not to increase the fee paid for a night visit because of the greater use of deputising services by general practitioners.

While respecting the need of some of my colleagues to use these services, particularly when their work load is large, I feel that there should be some recognition of the fact that many practitioners provide effective and efficient 24 -hour cover by duty rotation. It seems unjust that there should therefore be a penalty imposed on the profession as a whole on account of the supposed unsatisfactory financing, as I take it the Review Body considers the situation to be, of out-of-hours cover provided for a section of general practitioners by deputising services. I trust that the BMA has considered this matter and has an intention to provide the Review Body with evidence of the service provided by those of us who cover our own out-of-hours calls. It would seem that a differential fee would be appropriate to recognise this fact.

R D PARKIN

Sherburn-in-Elmet,
Leeds LS25 6ED

SIR,-The Daily Telegraph of 21 May featured a brief item to the effect that doctors and dentists were seeking an urgent meeting with $\mathrm{Mr}_{\mathrm{r}}$ Patrick Jenkin to discuss the Government's decision to cut their pay award from $9^{\circ}$, to $6 \%$, quoting the BMA.

I am a retired general practitioner who has suffered the many wrangles between governments and doctors since the initiation of the NHS, but I feel that this is one occasion where, whatever political views are held, the doctors should show their sense of responsibility and accept this cut as a purely temporary measure until our country achieves a more stable footing. This might help to set an example to other groups who are being asked to accept a limit of $6 \%$ or $7 \%$.

Except in cases of hardship retired pensioners might have to be asked to accept a temporary lowering of index linking.

\section{H C MAINGaY}

Norwich NR15 1DD

SIR,-The eleventh report of the Review Body states clearly that national economic circumstances are fully considered when formulating recommendations on pay. Paragraph 8 of the report says: "We take the view that our terms of reference require us to put forward recommendations for remuneration which, in all the circumstances, we believe to be right at the time. We do take account of the economic circumstances affecting the nation generally, as one of the range of relevant factors we have to consider in judging the appropriate levels of remuneration for the medical and dental professions." Presumably this is why. the award of $9 \%$ was considerably less than might have been expected, had the rise in inflation and the cost of living been the only factors in determining the level of the award.

The Prime Minister then takes the national economic circumstances into account for a second time, and quite unjustly further reduces the award to $6 \%$. The Review Body, which in former times would have undoubtedly resigned (and did), shrugs its shoulders philosophically, and the leaders of the BMA acquiesce without a struggle, piously hoping that "the profession would consider the Government decision .... in a responsible manner."

The net result is that the profession finds the spending power of its pay eroded by about $10 \%$ of last year's value - not enough to cause serious industrial unrest or even outraged comment. Nevertheless, when the procedure is repeated at annual intervals for the next three or four years (and a glance at the history of the last decade shows that this is inevitable) the profession will find itself again grossly underpaid, with all the demoralisation and threats of trade-union-style sanctions that go with this. We have seen it all in the past. Furthermore, when underpayment reaches the order of $50 \%$ it becomes virtually impossible for the most able negotiators and the most pliant government to put right.

Secondly, the BMA has laid itself open to the charge that it protests against Government interference in the Review Body pay award only when a Labour government is in office. The precedent of allowing a government to cut an independent pay award with virtually no opposition from the profession is incalculably dangerous.

Two steps must be taken as a matter of urgency. Firstly, the Government must be made aware of the extreme gravity of the decision it has taken in the eyes of the profession. It must understand that such action is unacceptable irrespective of the political colour of the party in power. Secondly, our negotiators must ensure that the pay award is paid at the full rates set out in the Review Body report but not implemented until August 1981 (or whatever date is appropriate) rather than being backdated to April. This will make certain that the $6 \%$ cash limit is not breached for the current year while ensuring that on 1 April 1982 we do not embark on another pay review while still trying to achieve the recommendations of the old.

\section{JAMES N JOHNSON Chairman, Mersey Regional Hospital} Junior Staff Committee

Liverpool L3 5SR

\section{Problems of overseas doctors}

SIR,-I have followed the debate on the problems of overseas doctors with great interest. Dr F I D Konotey-Ahulu (16 May, p 1621) points out that it is necessary to be "adopted" to attain a measure of success in the system. Professor George Dick (16 May, p 1622), through Medical Advisory and Research Consultants Limited, describes a way of getting adopted.

Adoption implies informal or formal sponsorship. Sponsorship can be made available only to a limited number of persons. It requires a chain of senior colleagues, as in the case of $\mathrm{Dr}$ Konotey-Ahulu, to see an aspirant through the system. The "goodwill" of a postgraduate dean, a regional medical officer, an area medical officer, and a district community physician respectively worked to advantage in my case. Only one of my sponsors had ever worked overseas. There was an equal number of doctors who felt unable to support or encourage me yet whom I have subsequently come to know as sympathetic and concerned persons in the cause of professionalism and adequate training for overseas doctors. The answer to the problem, in my view, is to strive to develop this goodwill in the British-born graduates towards overseas doctors.

The debate in the $B M \mathcal{F}$ has highlighted several issues. Are we ready to act on them?

\section{S S BAKHSHI}

Community Medicine (Environmental Health), Birmingham Area Health Authority (Teaching), Birmingham Area Heat

\section{Correction}

“Who Will Deliver Your Baby?"

Jennifer C Niall asks us to point out that she is not a doctor, as suggested in the letter by $\mathrm{Mr}$ W Love (16 May, p 1631), but a midwifery teacher. 